\title{
Potential RSM Projects; Utulei Beach Region, American Samoa
}

by Thomas D. Smith

PURPOSE: This Regional Sediment Management Technical Note (RSM-TN) identifies Potential RSM Projects (PRPs) that could be implemented in the Utulei Beach Region of American Samoa. A goal of the U.S. Army Corps of Engineers (USACE) RSM Program is to collaborate across the USACE with stakeholders and partners to identify strategies to integrate RSM opportunities into existing or new projects that lead to construction. The purpose of this technical note is to identify conceptual alternatives that could be refined and implemented through acquisition of appropriate federal authorizations, by other federal/territory partnerships, or by the private sector.

BACKGROUND: The USACE Honolulu District (POH) focused RSM investigations for FY16 on the Utulei Beach Region in American Samoa. While POH has previously investigated RSM opportunities along several regions in Hawaii, this project is the first in the U.S. Territory of American Samoa. The Utulei Beach Region is located inside Pago Pago Harbor on the Island of Tutuila, American Samoa, and extends from Tulutulu Point to Nuututai Point (Figure 1), approximately 0.8 mile of shoreline. PRPs of particular interest in the Utulei Beach Region include (1) sand source investigations (harbors, offshore sand, and upland sand), (2) sand recycling, and (3) sand pushing. The sediment of interest in this RSM-TN is sand sized and will be referenced interchangeably in the following text as sand or sediment.

SAND SOURCE INVESTIGATIONS: Environmental permitting must comply with both federal and Territory of American Samoa laws, policies, and regulations. Federal requirements will include coordination with the USACE, National Oceanic and Atmospheric Administration, National Marine Fisheries Service, U.S. Environmental Protection Agency, and U.S. Fish and Wildlife Service, at a minimum. Coordination with American Samoa environmental agencies such as the American Samoa Environmental Protection Agency (ASEPA), American Samoa Historic Preservation Office, and the American Samoa Department of Marine and Wildlife Resources (ASDMWR) will also need to be conducted. Compliance with environmental laws, policies, and regulations is a costly and time-consuming aspect of conducting beach nourishment and must be included in each project's schedule and budget. 


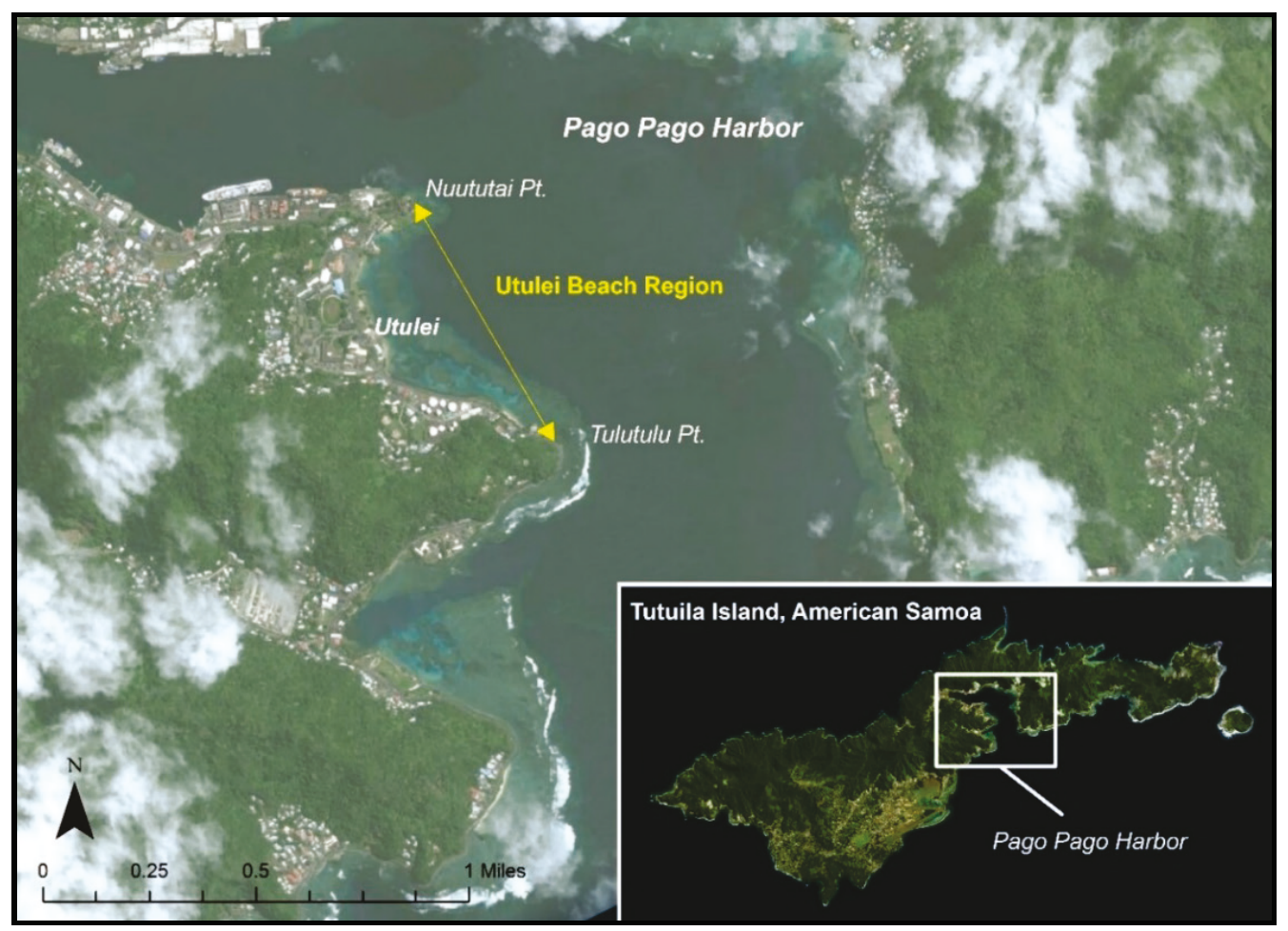

Figure 1. Utulei Beach Region, inside Pago Pago Harbor on Island of Tutuila, American Samoa.

Cultural acceptability is a critical aspect to the successful implementation of the PRPs presented in this RSM-TN. Stakeholder engagement is necessary to determine the acceptability of transporting dredged sediment (sand-sized) from a harbor located in one American Samoa village and placing along another village's shoreline. In some cases where harbor shorelines adjacent to a federal navigation project are eroding, sediment dredged from that harbor may be best utilized to mitigate that immediate shoreline erosion. In other cases, the shoreline adjacent to a federal navigation project may not be eroding, and the use of sediment dredged from that harbor for a distal beneficial use may be acceptable. Case-by-case assessment of cultural suitability will be required prior to implementation of a proposed PRP.

Harbors. There are two federally authorized navigation projects within 10 miles of the Utulei Beach Region. Auasi Small Boat Harbor (SBH) is on the southeast coast of the Island of Tutuila, approximately 8.8 miles from the study region (Figure 2). Aunuu SBH is on the west coast of the Island of Aunuu, approximately 9.0 miles from the study region (Figure 3). General navigation features at both harbors include an entrance channel and basin as well as protective coastal navigation structures. Based on a 2014 hydrographic survey, there are approximately 1,300 cubic yards (cy) and 1,200 cy of sediment above the authorized project depths at Auasi SBH and Aunuu SBH, respectively. This sediment can potentially be used to nourish the Utulei Beach Region depending upon its suitability, identification of a non-federal entity willing to pay the incremental cost above the Federal Standard, environmental permitting, and cultural acceptability of this PRP. Authorities associated with the Federal Standard are codified in the Code of Federal Regulations (CFR) Title 33, CFR 335-338. 


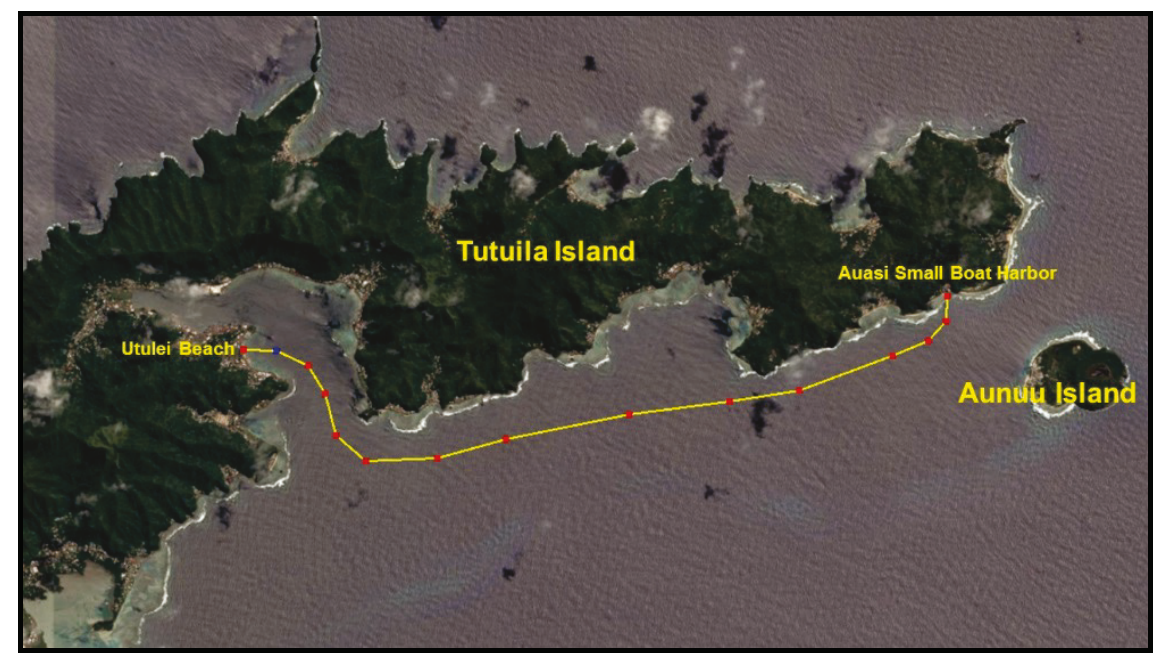

Figure 2. Location of Auasi SBH on the Island of Tutuila and the relative distance to the Utulei Beach Region via waterborne transport (approximately 8.8 miles).

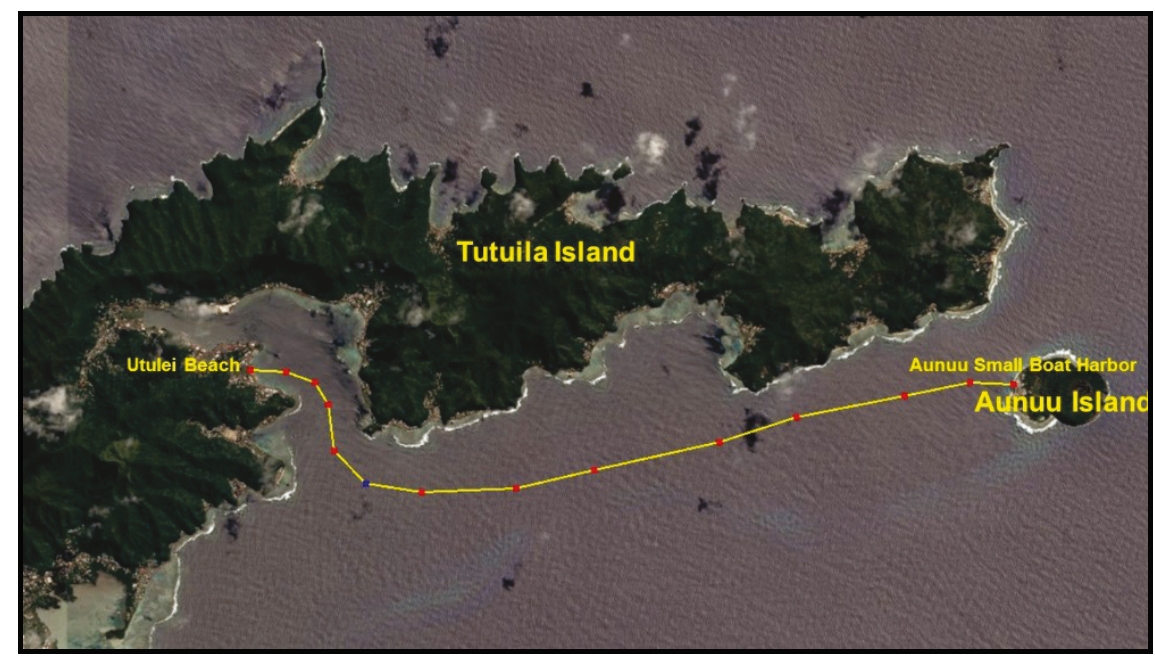

Figure 3. Location of Aunuu Small Boat Harbor on the Island of Aunuu and the relative distance to the Utulei Beach Region via waterborne transport (approximately 9.0 miles).

Suitability of dredged sediment for beach nourishment includes requirements for physical as well as chemical characteristics. American Samoa has the same type of standards as the United States, but various resource agencies have different concerns in different areas around the United States. The physical characteristics of the sediment must match the native sand on the receiving beach. The physical characteristics of interest include grain size, percent fines, color, and hardness. The chemical characteristics must be quantified to ensure that the dredged sediment does not contaminate the receiving beach. Sampling of the in situ sediment to be dredged will be conducted in association with the next operation and maintenance dredging event at both harbors. If the dredged sediment is to be considered for placement on a beach, an appropriate sampling plan needs to be developed and implemented. 
The Federal Standard requires the least costly environmentally acceptable placement/disposal option for the dredged sediment. Historically, sediment dredged from the federally authorized navigation projects in American Samoa has been placed in upland disposal areas. The incremental cost of placing the dredged sediment at a location other than that which is defined as the Federal Standard must be borne by a non-federal sponsor. The incremental cost includes the cost of transporting the sediment from each harbor and placing it on the target beach as well as the environmental permitting requirements associated with beach nourishment in American Samoa.

Offshore Sand. Beach quality sediment may be available offshore within the reach of existing dredging capabilities. For an offshore sand source to be economical, it must contain a minimum volume of suitable sand to offset mobilization, dredging, placement, and demobilization costs. In terms of unit cost (the total cost of all dredging operations divided by the volume of sediment dredged), the range of economical values in American Samoa is between $\$ 100$ to $\$ 200$ per cubic yard of sand. Preliminary offshore sand source investigations were previously conducted by the U.S. Geological Survey (USGS) (Dingler et al. 1986). The purpose of the study was to ascertain whether significant sand deposits exist outside the reef in water shallow enough to be dredged.

Both geophysical techniques (side scan sonar and seismic profiling) and scuba diving were used to search for shallow-water sand deposits. Diving enabled the survey team to inspect areas that looked interesting on the geophysical records and to collect sediment samples that could be analyzed for grain size and composition. Figure 4 shows the interpretation of seismic profiling in Faga'itua Bay, which indicates the presence of various sedimentary units that may be of interest. Figure 5 is a seismic profile taken in Se'etaga Bay. The seismic information was interpreted to represent a cover of hard pan sediment up to 1 meter $(\mathrm{m})$ (approximately 3 feet [ft]) thick extending along the seafloor. A thick layer ( 8 to $9 \mathrm{~m}$ [26 to $30 \mathrm{ft}$ ] in vertical extent) of homogeneous unconsolidated sediment appears to exist below the hard pan layer.

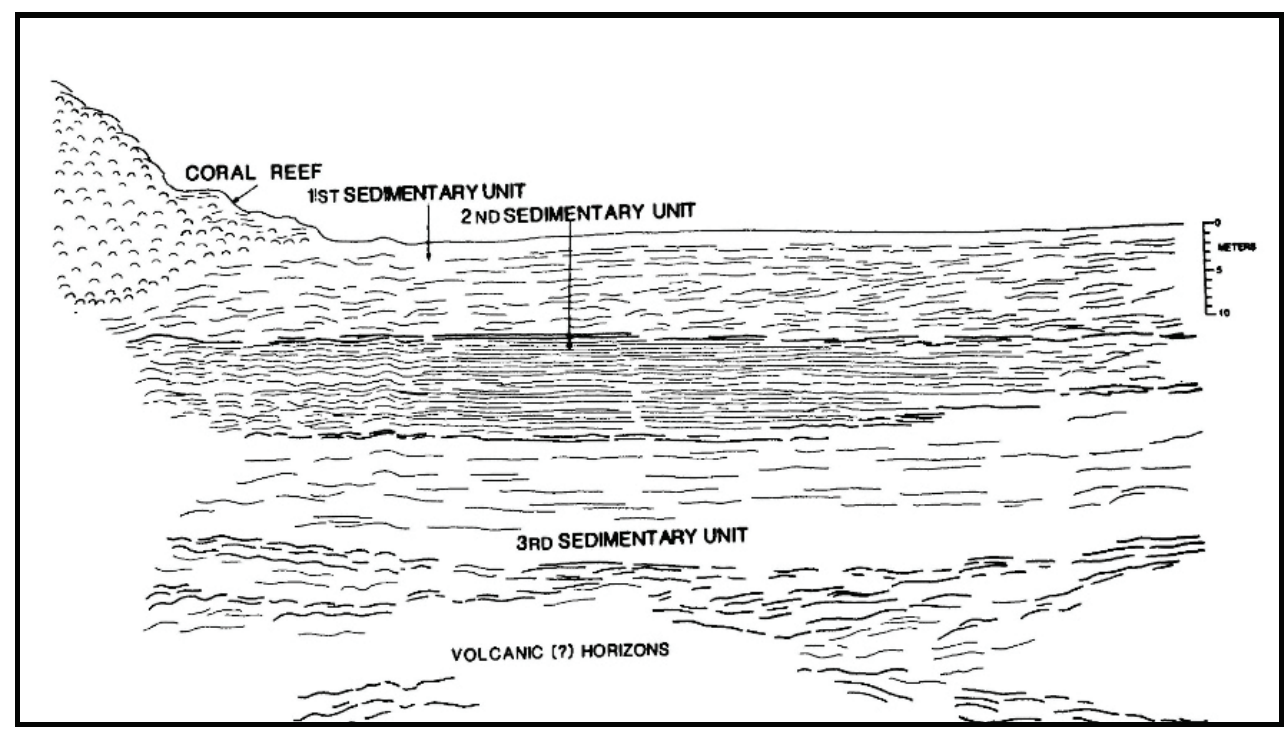

Figure 4. Seismic cross section for Faga'itua Bay (after Dingler et al. 1986). 


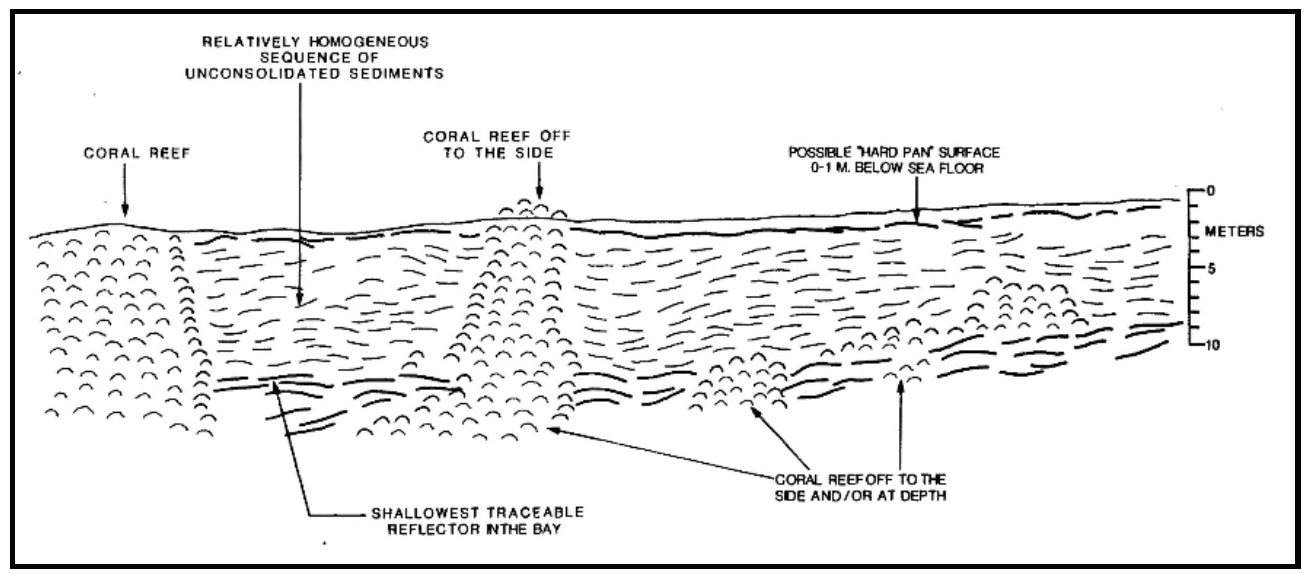

Figure 5. Seismic cross section for Se'etaga Bay (after Dingler et al. 1986).

The USGS (Dingler et al. 1986) determined that there may be a limited quantity of beach quality sediment located offshore of the Island of Tutuila that could be dredged for the purpose of beach restoration. The target offshore sand sources would need to be cored and analyzed to determine their exact extent and compatibility. The USGS (Dingle et al. 1986) did not address the environmental impacts related to removing sand from outside the reef. Additional studies will be required to estimate the effects of dredging on wave climate as well as on biota within the vicinity of the offshore sand sources.

Upland Sand. Viable upland sand sources have yet to be identified within economical haul distance from the Utulei Beach Region. Existing quarries on the Island of Tutuila do not contain beach quality sediment, and development of new quarries on the island is not anticipated in the near future. Private land potentially may be utilized if it contains suitable sand and is located within a reasonable haul distance from the Utulei Beach Region. Sampling, analysis, and permitting of any new borrow site will be required prior to its use. The Tafuna plain in south central Island of Tutuila may contain enough isolated areas of interest to conduct geotechnical investigations in search of sand.

SAND RECYCLING: A channel exists that runs parallel to shore that may contain sand from the adjacent reef and beach. The original purpose of creating the channel is not well known, but it is believed to have been excavated to provide either a safe swimming area or sediment for land reclamation. Sand recycling (Figure 6) involves reclaiming sand that accumulates in that channel.

The channel can be seen in Figure 6 along the inner edge of the reef, from the left of and extending under the "Sand Recycling" label. The label includes green arrows that point to and from the channel and beach. These green arrows in the figure indicate that sand would be dredged from the channel and placed on the beach. Its use as a sustainable sand source would have to be determined through geotechnical investigations to quantify physical and chemical suitability as well as volume availability. The rate of channel infilling could be quantified through annual hydrographic surveys taken over a number of years. The channel may be a sediment sink, but it also may be a sustainable resource as a borrow area for beach fill. 


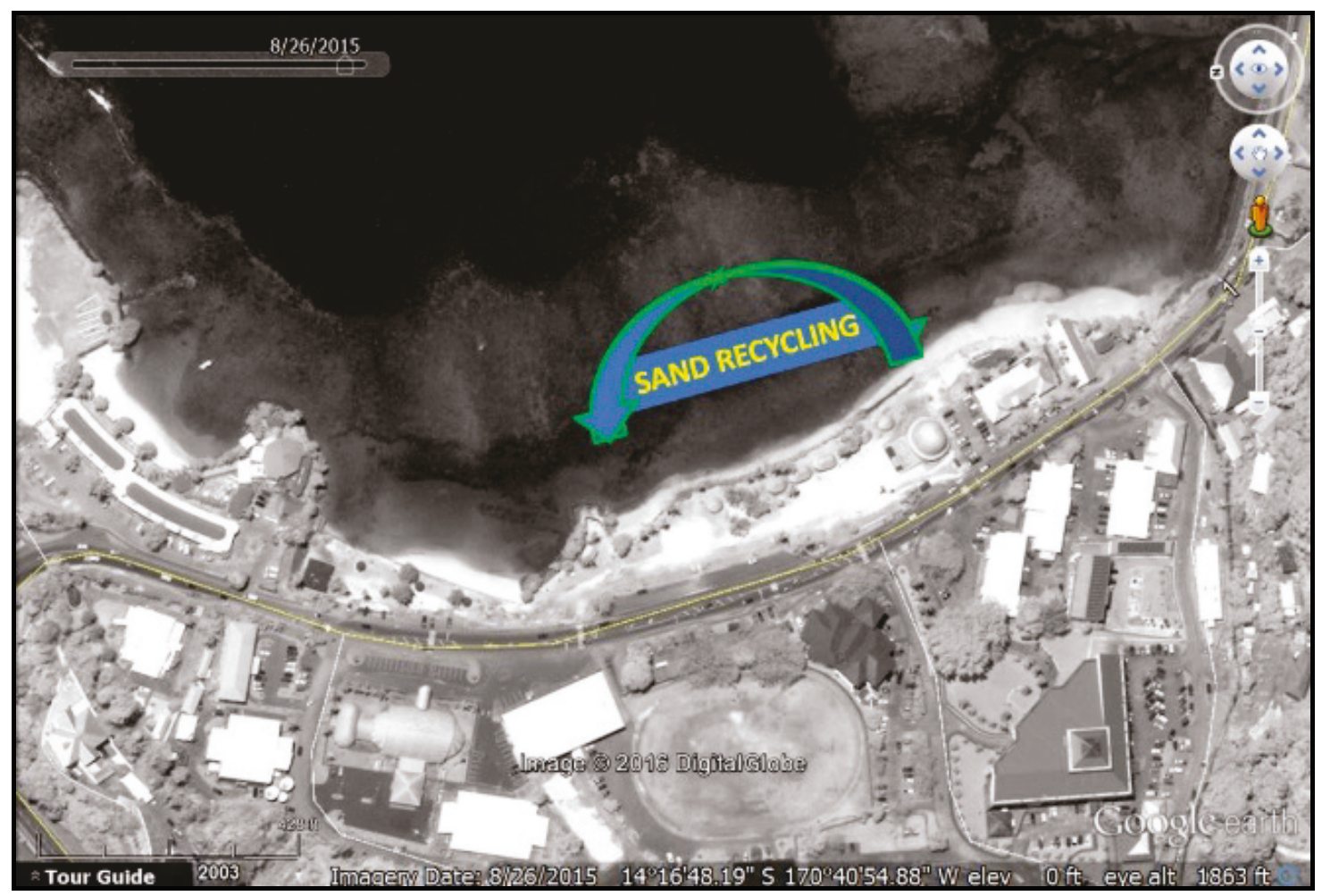

Figure 6. Schematic of sand recycling as a potential RSM project. The green arrows indicate that sand would be dredged from the channel and placed on the beach.

Implementation of this PRP would likely involve award of a contract to a company with the capability of transferring the sediment from the channel to the beach. Once on the beach, the sediment would be shaped to the lines and grades indicated in the contract documents. Negative aspects of sand recycling include potential impacts to both benthic habitat and adjacent shorelines.

SAND PUSHING: Sand pushing (often referred to as beach scraping) is the practice of pushing sand from the lower to the upper portion of the beach profile. This technique is symbolized in Figure 7 by yellow buckets pouring sand on the beach. The operation is typically carried out at or near low tide and is repeated if subsequent inspections indicate that the lower portion of the beach profile recovers over time.

This PRP could be implemented with a small crew and light construction equipment. During an advantageous low tide, a crew of two or three could utilize a bulldozer to scrape and push sand from the toe of the existing beach. The sediment could then be stacked along the upper portion of the beach profile to create a sand berm. The berm would be exposed to wave action during high tides and times of unseasonably large waves. Over time, the berm would disperse and provide nourishment to the lower portion of the beach profile. Alternatively, the sand could be spread into an even layer over the upper portion of the beach profile. This would result in the seaward extension of the shoreline in the approximate proportion of $1 \mathrm{ft}$ for every $0.4 \mathrm{cy}$ of sand placed per square foot of beach. Similarly to the sand recycling PRP, negative aspects of sand pushing include potential impacts to both benthic habitat and adjacent shorelines, and potential impacts to the profile itself. Additional numerical modeling and geotechnical investigations would be required prior to utilizing the area as a source of beach fill. 


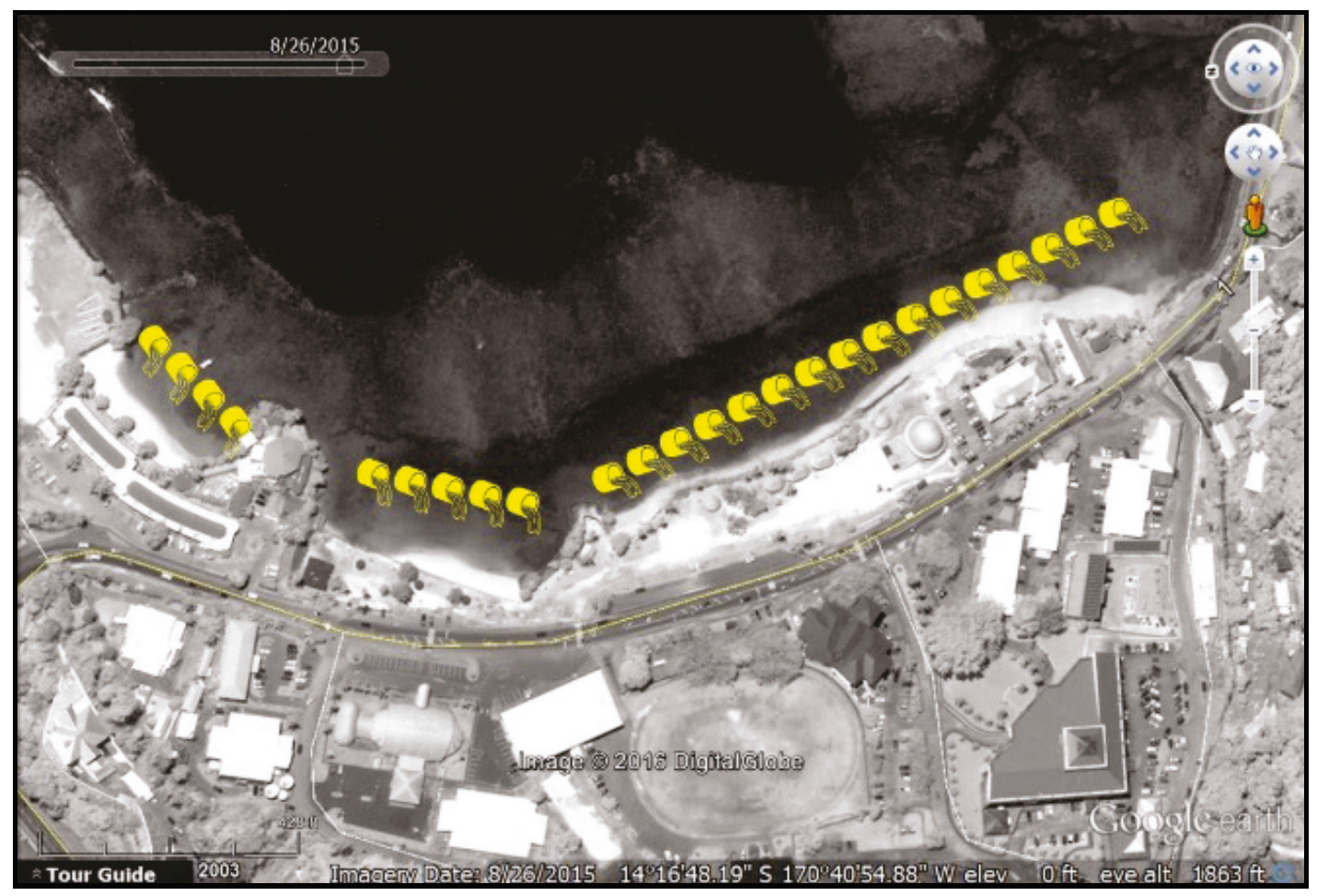

Figure 7. Schematic of sand pushing as a potential RSM project, symbolized by yellow buckets pouring sand onto the beach.

REGIONAL SEDIMENT MANAGEMENT WORKSHOP: An RSM workshop was held on 27 July 2016 in Pago Pago, on the American Samoa Island of Tutuila, where stakeholders discussed PRPs that might be implemented in the Utulei Beach Region. Participants of the workshop included POH; U.S. Army Engineer Research and Development Center (ERDC); American Samoa (AS) agencies including ASEPA; ASDMWR; AS Department of Commerce; AS Department of Agriculture; AS Department of Public Safety, Marine Patrol; AS Department of Public Works; AS Department of Youth and Women Affairs; AS Government, Visitors Bureau; AS Community College; AS Coral Reef Advisory Group; AS Power Authority; AS Senate; and the Sadie's Hotel.

Three workshop breakout topics were discussed. The topics considered for implementation of PRPs included (1) engineering considerations, (2) environmental considerations, and (3) funding considerations.

Engineering Considerations. Historical information discussed during the workshop provided context for consideration of engineering solutions to the shoreline erosion issues being experienced in the Utulei Beach Region. Anthropogenic impacts within the region have been significant. Prior to major shoreline modifications, the region was a coastal marshland. Land reclamation efforts during the 1960s included the placement of fill and elimination of marshland within and adjacent to the region. A channel was dredged just offshore of Utulei Beach for either land reclamation purposes or provision of a safe swimming area. A number of coastal structures have been constructed in the region. They include seawalls, groins, and a submerged offshore breakwater. Additionally, it was emphasized that land ownership offshore and within the upland portions of the region needs to be determined early in the PRP planning process. 
It was recommended that the recession rate for the region be quantified and the impacts of existing coastal structures should be evaluated. RSM investigations for the region indicate that the shoreline has experienced chronic recession over the past 20 years and is currently comprised of reaches of sand and derelict seawalls. Numerical modeling results ${ }^{1}$ show that littoral transport is generally from south to north during all tidal phases when significant wave energy is present offshore of Pago Pago Harbor.

Implementation of any PRP will require identification of suitable quality and quantity of sediment. Potential sand sources include Pala Lagoon, stream mouths, upland and offshore borrow areas, and harbors (Auasi Harbor and Aunuu Harbor). Pala Lagoon is bordered by Coconut Point sand spit on its eastern limit. The spit is actively growing to the south and limits the exchange of tidal waters into the lagoon. The lagoon is one of the most sediment-rich marine environments in American Samoa. At this time, more information is required as to the quantity and quality of the sediment in and around the lagoon.

Workshop attendees were not aware of any commercial upland sand sources on the island, but sediment may be available on privately owned land. The use of such privately owned sources of sand would have to be coordinated with individual land owners and permitted by applicable territory and federal agencies. Offshore borrow areas may exist within a reasonable distance from the Utulei Beach Region, but they would have to be fully developed based on engineering characteristics of the sediment and environmental concerns for their use. The two SBH located within 10 miles of the region could potentially provide beach quality sand to the region. Restricting the use of dredged sediment beyond the immediate vicinity of these harbors may be a limiting factor to their use within the region.

Beach sand mining is a practice that is used to extract sand from shorelines for such uses as road construction, golf course maintenance, and land reclamation. Beach sand is also used to make concrete for various other applications. Beach sand mining is a direct cause of erosion and also impacts the local wildlife. For example, sea turtles depend on sandy beaches for their nesting. Removal of physical coastal barriers such as dunes has led to flooding of beachside communities and in some cases, resulted in decreased tourism. Sand mining is regulated by law in many places but is still often done illegally. Territorial and federal laws and regulations applicable to beach sand mining in American Samoa should be reviewed and summarized for public outreach purposes. Village chiefs and elders can take the lead to educate community members on the economic and environmental impacts of beach sand mining. Other types of territory and federally sponsored public outreach should also be implemented to eliminate the practice of beach sand mining in American Samoa. However, traditional uses of beach sand should not be prohibited without careful consideration.

Practices such as back-passing beach quality sand from stream mouths back onto updrift adjacent shorelines may be acceptable if conducted properly. There are many stream mouths on the Island of Tutuila coast where sediment deposits during periods of limited rainfall. The stream mouth at the village of Aua in Pago Pago Harbor is one example. Although there are limited supplies of sediment at these stream mouths, volumes on the order of 50 to 100 cy may be available at each site at any time. These sites may serve as sustainable sand sources for small quantities of sediment in the future.

${ }^{1}$ Molina, L. K., and J. H. Podoski. In preparation. American Somoa RSM: Numerical Modeling of Waves and Currents in the Utulei Beach Region. ERDC/Technical Note RSM. Vicksburg, MS: U.S. Army Engineer Research and Development Center. 
Other PRPs than those described above were discussed at the workshop. They included living shoreline projects that are comprised of shoreline stabilization measures such as trees, shrubs, and sand dunes. If sand has been mined from the beaches in the Utulei Beach Region, a similar quantity of sediment should be placed back within the region in the future. Given the nonavailability of upland sand sources in the region, retreat from the shoreline should be considered as a viable non-structural alternative. Retreat from the shoreline would also serve to accommodate future sea level rise that is predicted for the region. This would include the removal of the derelict coastal structures in the region and allowing the beach to naturally adjust to wave and current action. Additional PRPs may be identified as RSM concepts are introduced and promulgated throughout American Samoa.

Environmental Considerations. Past development activities in the project area include dredging operations in the nearshore reef area and the installation of a wastewater discharge pipeline in Gataivai (P Pacific Consultants 2015). The environmental impacts of proposed PRPs must be identified, and in some cases mitigation for those impacts may be required. Two of the most significant environmental resources in the Utulei Beach Region are coral and seagrass (Figure 8). Corallith fields and coral rubble are located on the reef flat and in the nearshore. Seagrass is spread out in shore parallel patches off the central and southern portions of the region. The seagrass is reported to be a rare species in American Samoa. The species has relatively short blades and has proven to be difficult to transplant successfully ${ }^{1}$. It was noted that the prolific seagrass may be the beneficiary of nutrients contained in discharge from the nearby water treatment plant. Both the coral and seagrass can be negatively impacted by siltation and shoaling of sandy sediment. Therefore, any activities involving placement of sand within the Utulei Beach Region must consider the impacts on these and other marine organisms.

Environmental impacts need to be predicted prior to, and monitored during, the implementation of proposed PRPs. Numerical modeling results from the ERDC Coastal Modeling System (CMS) Wave and Flow suite of models (Demirbilek and Rosati 2011) for the Utulei Beach Region are documented in a separate technical note ${ }^{2}$. The wave and current fields predicted by the CMS models are valuable indicators of the sediment transport regime in the region. Overall, model results indicate that net sediment transport is from south to north during all tide cycles under the majority of incident wave conditions. The CMS Particle Tracking Model (MacDonald et al. 2006) could be used to further refine predictions on the fate of sand placed within the region. In addition to pre-project modeling, baseline and with-project benthic habitat monitoring within and adjacent to the region should be undertaken in concert with the implementation of a proposed PRP. Strategic placement of sand was one suggestion to minimize the impacts of a PRP. Another suggestion was to start with small amounts of beach fill and assess those associated impacts prior to increasing the fill volume.

\footnotetext{
${ }^{1}$ Ms. Alice Lawrence. Coral Reef Advisory Group. American Somoa. Personal communication. 27 July 2016.

${ }^{2}$ Molina, L. K., and J. H. Podoski. In preparation. American Somoa RSM: Numerical Modeling of Waves and Currents in the

Utulei Beach Region. ERDC/Technical Note RSM. Vicksburg, MS: U.S. Army Engineer Research and Development Center.
} 


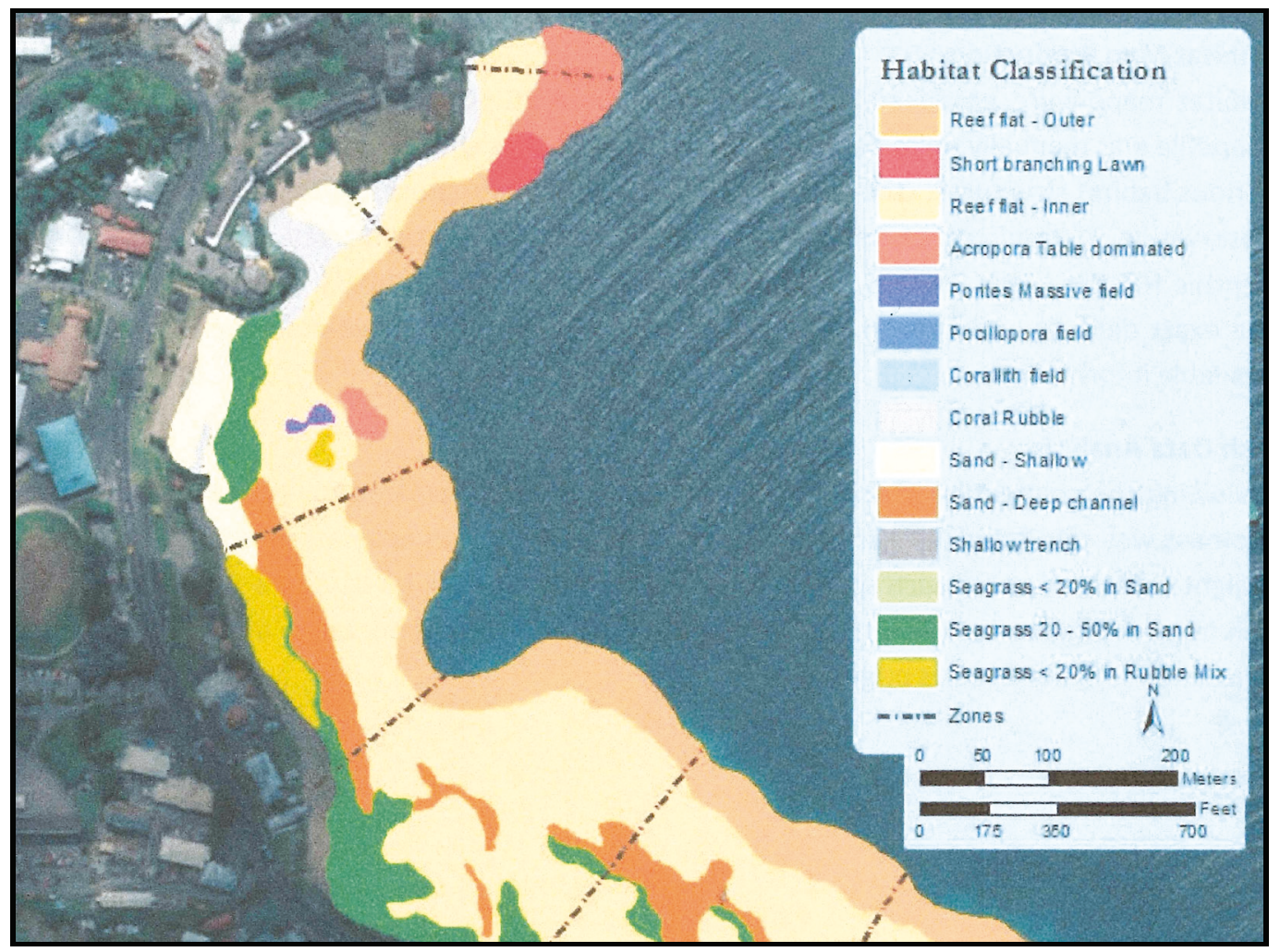

Figure 8. Benthic habitat map for the Utulei Beach Region, American Samoa (after P Pacific Consultants 2015).

Funding Considerations. Funding in pursuit of an RSM project for the Utulei Beach Region has not been identified. If dredged sediment from a federally authorized navigation project is to be used, a non-federal sponsor must be identified. In compliance with the Federal Standard, the non-federal sponsor would pay the additional cost of placing the dredged sediment in the region (over that of the least-cost disposal option). Total funding for any of the other PRPs described in this technical note would have to be secured. Potential sources of funding for the projects include the American Samoa Visitors Bureau; U.S. Department of the Interior, Capital Improvement Program; U.S. Office of Insular Affairs; U.S. National Parks Service; and the cruise ship industry. Fines generated from enforcement of sand mining laws were also identified as a possible source of funding.

CONCLUSIONS: The Utulei Beach Region was the initial focus for RSM in American Samoa. Shoaling at federally authorized $\mathrm{SBH}$ in the territory is relatively slow (nominally 1,000 to 2,000 cy per year). Beneficial use has been limited to traditional uses of dredged sediment stockpiled at these projects. Auasi and Aunuu Small Boat Harbors are potential sources for sand to restore Utulei Beach, but it will be 5 to 10 years before these harbors need to be dredged. Offshore and upland sources may also prove to be viable borrow areas for implementation of PRPs in the region. Of the PRPs presented in this technical note, sand pushing would be one of the more readily implemented. Assuming all required territory and federal permits are in place, sand pushing could be accomplished with a small crew and light construction equipment over multiple tidal cycles. Impacts of the mechanical movement of the resulting small quantities of beach sand could be monitored in real time and appropriate operational modifications implemented. It is recommended that other longer-term PRPs be investigated and pursued as deemed appropriate. 
ADDITIONAL INFORMATION: This Regional Sediment Management Technical Note (RSMTN) was prepared as part of the USACE National RSM Program, and was written by Thomas D. Smith, U.S. Army Corps of Engineers Honolulu District (POH), Honolulu, HI, with input from the American Samoa RSM Project Delivery Team. David A. Lau is the USACE Pacific Ocean Division RSM point of contact. Additional information pertaining to the POH RSM investigations can be found at http://rsm.usace.army.mil/Hawaii. Information regarding the USACE National RSM Program can be found at http://rsm.usace.army.mil.

Questions regarding this RSM-TN or the USACE RSM Program may be addressed to the following:

Thomas D. Smith (POH RSM POC)

Linda S. Lillycrop (USACE National RSM Program Manager)
Thomas.D.Smith@usace.army.mil

Linda.S.Lillycrop@usace.army.mil

This U.S. Army Engineer Research and Development Center (ERDC), Coastal and Hydraulics Laboratory (CHL), RSM Technical Note should be cited as follows:

Smith, T. D. 2018. Potential RSM Projects; Utulei Beach Region, American Samoa. ERDC/TN RSM-18-5. Vicksburg, MS: U.S. Army Engineer Research and Development Center. http://dx.doi.org/10.21079/11681/26601

\section{REFERENCES}

Demirbilek, Z., and J. D. Rosati. 2011. Verification and Validation of the Coastal Modeling System: Report 1; Summary Report. ERDC/CHL TR-11-10. Vicksburg, MS: U.S. Army Engineer Research and Development Center. http://acwc.sdp.sirsi.net/client/en_US/search/asset/1005704.

Dingler, J. R., S. C. Wolf, and D. Carlson. 1986. Offshore Sand Resources along the South Shore of Tutuila Island, American Samoa. Open-File Report 86-112. Washington, DC: U.S. Department of the Interior, Geological Survey. https://pubs.usgs.gov/of/1986/0112/report.pdf.

MacDonald, N. J., M. H. Davies, A. K. Zundel, J. D. Howlett, Z. Demirbilek, J. Z. Gailani, T. C. Lackey, and J. Smith. 2006. PTM, Particle Tracking Model: Report 1; Model Theory, Implementation, and Example Applications. ERDC/CHL TR-06-20. Vicksburg, MS: U.S. Army Engineer Research and Development Center. http://acwc.sdp.sirsi.net/client/search/asset/1000777.

P Pacific Consultants. 2015. Marine Biological Assessment of Utulei-Gataivai, American Samoa. Tafuna, Island of Tutuila, American Samoa.

NOTE: The contents of this technical note are not to be used for advertising, publication, or promotional purposes. Citation of trade names does not constitute an official endorsement or approval of the use of such products. 